\title{
EVALUASI PENGARUH VARIASI KONSENTRASI PATI BIJI CEMPEDAK (ARTHOCARPUS CHAMPEDEN) SEBAGAI BAHAN PENGISI PADA FORMULASI TABLET PARACETAMOL
}

\section{Evaluation of the Effect of Variation in Cempedak Seed (Arthocarpus Champeden) Starch Concentration as a Filler in Paracetamol Tablet Formulation}

\author{
Noval ${ }^{*}$ \\ Rizka Appriliani \\ Husda Oktaviannoor ${ }^{3}$ \\ $*_{1,2,3}$ Sari Mulia University, \\ Banjarmasin City, South \\ Borneo 70238, Indonesia \\ email: \\ rizkaappriliani9@gmail.com
}

\begin{abstract}
Abstrak
Tanaman cempedak banyak tersebar di wialyah Indonesia, salah satunya adalah Kalimantan. Cempedak merupakan tanaman tropi, sehingga potensinya bisa digunakan sebagai zat tambahan pada pembuatan sediaan farmasi. Penelitian sebelumnya memanfaatkan pati biji cempedak sebagai bahan pengikat pada formulasi tablet. Penelitian ini bertujuan untuk mengetahui pengaruh variasi konsentrasi dan konsentrasi optimum dari pati biji cempedak (Arthocarpus champeden) sebagai bahan pengisi formulasi tablet Paracetamol. Penelitian menggunakan rancangan True Eksperimental Design dengan desain posttest-only control group design. Pembuatan tablet menggunakan metode granulasi basah. Analisis data menggunakan uji one-way ANOVA yang dilanjutkan dengan uji LSD serta uji Kruskal-Wallis $H$ yang dilanjutkan dengan uji Mann Whithney Tes sebagai uji turunan dari one-way ANOVA. Evaluasi granul meliputi organoleptik, sifat alir, uji pengetapan, dan uji sudut diam. Hasil evaluasi granul menunjukkan bahwa granul yang dihasilkan dari tiap formulasi sesuai dengan persyaratan. Evaluasi tablet meliputi organoleptik, keseragaman bobot, kekerasan tablet, kerapuhan dan waktu hancur. Hasil evaluasi tablet menunjukkan bahwa konsentrasi maksimum pati biji cempedak terdapat pada $\mathrm{FI}$ karena menunjukkan hasil evaluasi yang sudah sesuai dengan persyaratan. Pada evaluasi keseragaman bobot dan kekerasan tablet dengan uji Kruskal Wallis $H$ dan uji Mann Whithney Tes menunjukkan hasil bahwa adanya perbedaan pada setiap formula dengan nilai $P<0,05$. Hasil evaluasi kerapuhan tablet dan waktu hancur dengan uji one-way ANOVA dan uji LSD menunjukkan adanya perbedaan pada setiap formula dengan nilai $P<0.05$. Pati biji cempedak (Arthocarpus champeden) dapat digunakan sebagai bahan pengisi pada pemuatan tablet Paracetamol.
\end{abstract}

Kata Kunci:

Biji cempedak (Arthocarpus

champeden)

Bahan pengisi

Tablet Paracetamol.

\section{Keywords:}

Cempedak seeds (Arthocarpus

champeden)

Falling material

Paracetamol tablets

\begin{abstract}
Cempedak plants are widely distributed in Indonesia, one of which is Kalimantan. Cempedak is a tropical plant, so its potential can be used as an additive in the manufacture of pharmaceutical preparations. Previous studies used cempedak seed starch as a binding agent in tablet formulations. This study aims to determine the effect of variations in concentration and optimum concentration of Cempedak seed starch (Arthocarpus champeden) as a filler for Paracetamol tablets. The study used a True Experimental Design design with a posttest-only control group design. Making tablets using the wet granulation method. Data analysis used the one-way ANOVA test followed by the LSD test and the Kruskal-Wallis $\mathrm{H}$ test which continued with the Mann Whithney Test as a derivative test of the one-way ANOVA. Granule evaluation includes organoleptic, flow properties, tapping test, and stationary angle test. The results of the evaluation of the granules produced granules produced from each formulation are in accordance with the requirements. Tablet evaluation included organoleptic, uniformity in weight, hardness of tablet, friability and disintegration time. The results of the tablet evaluation showed that the maximum concentration of cempedak seeds was found in $\mathrm{Fl}$ because it showed the evaluation results that were in accordance with the requirements. In evaluating the uniformity of weight and hardness of tablets with the Kruskal Wallis $H$ test and the Mann Whithney Test, the results show that there are differences in each formula with a $P$ value $<0.05$. The results of evaluation of tablet friability and disintegration time with one-way ANOVA test and LSD test showed differences in each formula with a $P$ value $<0.05$. Cempedak seed starch (Arthocarpus champeden) can be used as a filler in the loading of Paracetamol tablets by wet granulation method.
\end{abstract}

(C) year The Authors. Published by Institute for Research and Community Services Universitas Muhammadiyah Palangkaraya. This is Open Access article under the CC-BY-SA License (http://creativecommons.org/licenses/by-sa/4.0/). DOI: https://doi.org//0.33084/jsm.vxix.xxx. 


\section{PENDAHULUAN}

Bahan tambahan yang digunakan dalam sediaan tablet dapat berupa bahan pengisi, bahan pengikat, bahan penghancur, bahan pelicin, bahan pewarna, bahan perasa dan bahan penyalut jika diperlukan. Bahan tambahan yang umum digunakan dalam pembuatan tablet masih merupakan bahan impor yang relatif mahal. Sekitar $90 \%$ zat aktif maupun bahan tambahan di Indonesia masih impor dari luar negeri untuk mendapatkannya (Noor Laili, 2017).

Bahan tambahan yang ditambahkan pada pembuatan tablet dimaksudkan untuk mendapatkan tablet yang baik dan berkualitas serta memenuhi persyaratan yang ditetapkan untuk sediaan tablet, digunakan jika zat aktif memiliki dosis yang tidak cukup untuk membentuk bulk dan untuk memperbaiki daya kohesi agar tablet dapat dikempa langsung untuk memicu aliran. Umumnya bahan tambahan yang digunakan pada pembuatan tablet memiliki karakteristik seperti harus bersifat netral, tidak berbau, tidak berasa dan sedapat mungkin tidak berwarna (Yuliestia, 2010).

Eksipien yang umumnya digunakan sebagai bahan pengisi adalah laktosa. Laktosa sering digunakan sebagai bahan pengisi tablet karena tidak bereaksi terhadap hampir semua bahan obat, yang digunakan baik dalam bentuk hidrat atau anhidrat (Yuliestia, 2008).

Cempedak atau dengan nama lain Artocarpus champeden merupakan salah satu jenis tanaman asli dari Indonesia yang tersebar di daerah Kalimantan, Sumatera, Sulawesi, Maluku dan Jawa. Menurut Statistik Produksi Hortikultura tahun (2015) jumlah produksi cempedak pada tahun 2014 sebanyak 644.29I ton. Cempedak merupakan salah satu tanaman tropis yang ada di Indonesia, sehingga potensi tersedianya biji cempedak cukup besar. Pemanfaatan tanaman sebagai bahan baku obat memang akan terus berkembang karena banyaknya manfaat dari tanaman (Noval et al., 2019). Selain itu, mengingat kekayaan alam yang dimiliki oleh Indonesia untuk menghasilkan produk atau bahan baku obat (Noval, Melviani, Novia, Syahrina, 2020).
Paracetamol atau yang dikenal dengan nama asetaminofen merupakan zat aktif yang umumnya digunakan untuk mengobati sakit kepala dan nyeri ringan seperti pilek dan flu (Samar, et al. 2013). Paracetamol merupakan bahan obat yang memiliki karakteristik kompaktibilitas yang kurang baik dan sifat alir yang buruk. Mengatasi hal tersebut pembuatan tablet Paracetamol menggunakan metode granulasi basah. Metode ini mengandung bahan pengikat dalam bentu kmucilago yang dapat meningkatkan kohesivitas agar kekerasannya semakin tinggi (Sugiyono, dkk. 20l2).

Tingginya kebutuhan terhadap bahan tambahan di Indonesia membuat dorongan terhadap peneliti untuk dapat menghasilkan eksipien dari bahan kekayaan lokal. Pada penelitian ini pati dari biji cempedak yang digunakan diharapkan memiliki kemampuan sebagai bahan pengisi pada pembuatan tablet Paracetamol dan mengetahui pengaruh penggunaan pati biji cempedak terhadap sifat fisik tablet serta konsentrasi optimum dari pati biji cempedak yang dapat memenuhi persyaratan sebagai bahan pengisi tablet.

\section{METODOLOGI}

Alat

Timbangan analitik (AD-600), mortar, stemper, ayakan dengan no. mesh 44 dan 60, oven, Hardness Tester, Feiability Tester (TFT-2-D), Granul Flow Tester (GFT-I00AU), Tap Density Tester (TDT-2-H), Disintregration Tester dan mesin pencetak tablet.

\section{Bahan}

Paracetamol, amilum, laktosa, pati bji cempedak, amilum kering, magnesium stearate, talkum, dan gelatin.

\section{Prosedur Kerja}

a. Pembuatan Pati Biji Cempedak

Biji cempedak dicuci dan dikupas. Timbang I kg biji cempedak, kemudian diparut. Tambahkan air kemudian diremas-remas, setelah itu disaring menggunakan kertas saring. Filtrat yang didapat didiamkan selama 6-12 untuk mengendapkan patinya. Residu pati tersebut diambil, kemudian dikeringkan dalam oven pada suhu $50^{\circ} \mathrm{C}$ selama 6 
Rizka Appriliani, Noval, Husda Oktaviannoor. 2021. Evaluation of the Effect of Variation in Cempedak Seed (Arthocarpus Champeden) Starch Concentration as a Filler in Paracetamol Tablet Formulation

jam hingga pati kering kemudian ayak dengan ayakan

no. mesh 44 .

b. Pembuatan Granul

Campurkan Paracetamol, pati biji cempedak dan amilum, kemudian ditambahkan gelatin sebagai bahan pengikat sedikit demi sedikit kedalam campuran sampai terbentuk massa granul yang homogen. Granul basah diayak menggunakan ayakan no 16, kemudian dikeringkan dalam oven pada suhu

Tabel I. Formulasi Tablet Paracetamol $60^{\circ} \mathrm{C}$ selama 5 jam. Granul yang telah dikeringkan diayak dengan ayakan no 18, kemudian ditambahkan amilum, talkum, dan magnesium stearat melalui ayakan no 40 , selama 5 menit.

c. Pembuatan Tablet

Granul dicetak dengan mesin pencetak tablet dengan bobot rata-rata $500 \mathrm{mg}$, kemudian dilakaukan evaluasi terhadap tablet (Nailul Magfiroh, 2018).

\section{Formulasi tablet (\%)}

\begin{tabular}{|c|c|c|c|c|c|c|c|}
\hline \multirow{2}{*}{ Bahan } & \multirow[b]{2}{*}{+} & \multirow[b]{2}{*}{-} & \multirow[b]{2}{*}{$\mathbf{F I}$} & \multirow[b]{2}{*}{$\mathbf{F 2}$} & \multirow[b]{2}{*}{$\mathbf{F 3}$} & \multirow[b]{2}{*}{$\mathbf{F 4}$} & \multirow[b]{2}{*}{ F5 } \\
\hline & & & & & & & \\
\hline Paracetamol (mg) & 250 & 250 & 250 & 250 & 250 & 250 & 250 \\
\hline Amilum (bahan penghancur) & 10 & 10 & 10 & 10 & 10 & 10 & 10 \\
\hline Lactosa (bahan pengisi) & 12 & - & - & - & - & - & - \\
\hline Pati biji cempedak (bahan pengisi) & - & - & 4 & 12 & 20 & 28 & 36 \\
\hline Amilum kering (bahan penghancur) & 5 & 5 & 5 & 5 & 5 & 5 & 5 \\
\hline Mg stearate & 5 & 5 & 5 & 5 & 5 & 5 & 5 \\
\hline Talkum & 10 & 10 & 10 & 10 & 10 & 10 & 10 \\
\hline Gelatin (bahan pengikat) & 15 & 15 & 15 & 15 & 15 & 15 & 15 \\
\hline Total bobot tablet & 500 & 500 & 500 & 500 & 500 & 500 & 500 \\
\hline
\end{tabular}




\section{Evaluasi Granul}

a. Organoleptis

Pemeriksaan meliputi bentuk, warna, rasa dan bau (Kurniawati et al., 2020).

b. Kadar air

Menimbang 5 g granul, dimasukkan kedalam lemari pengering seperti oven hingga bobot konstan pada suhu $105^{\circ} \mathrm{C}$ selama 2 jam.

c. Sifat alir

Granul kering ditimbang $25 \mathrm{~g}$, masukkan dalam corong pada alat uji waktu alir dalam keadaan tertutup. Buka penutup corong, biarkan granul mengalir dan catat waktu yang digunakan granul untuk mengalir (Sapri, 20 I2).

d. Uji pengetapan

Granul kering dimasukkan ke dalam gelas ukur yang telah di letakkan di atas alat volumenometer untuk uji pengetapan. Granul diberikan getaran mekanik hingga volume granul konstan.

e. Uji sudut diam

Granul kering yang dihasilkan dari corong di atas bidang horizontal membentuk tumpukan granul. Ukur tinggi kerucut dan diameter serbuk yang terbentuk dengan jangka sorong.

\section{Evaluasi Fisik Tablet}

a. Organoleptis

Menurut Depkes RI (1995) pemeriksaan organoleptis granul meliputi bentuk, warna, rasa dan bau (Noval et al., 2020).

b. Keseragaman bobot

Timbang 20 tablet satu per satu. Dihitung bobot rata- rata tablet, kemudian dihitung persentase penyimpangan bobot tablet.

c. Kekerasan tablet

Masing - masing tablet dari 10 tablet diletakan tegak lurus diantara anvil dan punch, kemudian putar sekrup pengatur sampai tanda lampu stop menyala untuk menjepit tablet. Setelah itu, knop ditekan sampai tablet pecah. Baca angka yang ditunjukkan pada jarum penunjuk skala yang adap ada alat (Yuliestia, 2012).

d. Kerapuhan tablet

Bersihkan 20 tablet dari debu, kemudian ditimbang satu per satu tablet. Lalu dimasukkan kedalam alat uji kerapuhan tablet. Atur alat dengan kecepatan putaran $25 \mathrm{rpm}$ selama 4 menit. Hitung persen tahan kehilangan bobot tablet setelah pengujian (Noorjannah \& Noval, 2020).

e. Waktu hancur

Pengujian waktu hancur dilakukan dengan cara memasukkan enam tablet kedalam keranjang berisi cairan yang disesuaikan dengan cairan tubuh, kemudian keranjang ditutun-naikkan secara teratur pada suhu $37^{\circ} \mathrm{C}$ hingga tablet hancur (Noorjannah \& Noval, 2020).

\section{Analisis Data}

Data hasil evaluasi sifat fisik tablet Paracetamol yang diperoleh selanjutnya dianalisis dengan analisis statistika. Analisis data dalam penelitian ini menggunakan uji OneWay ANOVA pada tingkat kepercayaan 95\% untuk mengetahui perbedaan yang bermakna antar formulasi tablet (Adi, dkk. 20l7).

\section{HASIL DAN PEMBAHASAN}

\section{Evaluasi Granul}

a. Pemeriksaan organoleptik

Berdasarkan table 2. granul yang didapat pada setiap formula berwarna putih. Warna putih dihasilkan dari zat aktif dan bahan tambahan yang digunakan berwarna putih. Granul berbentuk granul bulat yang disebabkan oleh proses granulasi dengan cara pengayakan dengan mesh. Granul memiliki bau seperti pati pada umumnya.

Tabel 2. Hasil uji pemeriksaan organoleptik

\begin{tabular}{cccc}
\hline \multirow{2}{*}{ Formulasi } & \multicolumn{3}{c}{ Pemeriksaan Organoleptik } \\
\cline { 2 - 4 } & Bentuk & Warna & Bau \\
\hline $\mathrm{K}(+)$ & Granul & Putih & Pati \\
\hline $\mathrm{K}(-)$ & Granul & Putih & Pati \\
\hline FI & Granul & Putih & Pati \\
\hline
\end{tabular}


Rizka Appriliani, Noval, Husda Oktaviannoor. 2021. Evaluation of the Effect of Variation in Cempedak Seed (Arthocarpus Champeden) Starch Concentration as a Filler in Paracetamol Tablet Formulation

\begin{tabular}{clll}
\hline F2 & Granul & Putih & Pati \\
\hline F3 & Granul & Putih & Pati \\
\hline F4 & Granul & Putih & Pati \\
\hline F5 & Granul & Putih & Pati \\
\hline
\end{tabular}

b. Uji kadar air

Berdasarkan tabel 3. hasil uji kadar air untuk formula $\mathrm{K}(+)$ sebesar $3.37 \%, \mathrm{~K}(-)$ sebesar $3.35 \%$, FI sebesar $3.78 \%$, F2 sebesar $2.3 \%$, F3 sebesar 2.68\%, F4 sebesar 3.10\%, F5 sebesar $3.08 \%$. Kandungan air pada semua formula menghasilkan granul yang baik dan memenuhi persyaratan kandungan air pada metode granulasi basah menurut Farmakope Indonesia (1979) adalah sebesar $2-4 \%$.

c. Uji sifat alir

Berdasarkan tabel 3. hasil yang didapatkan menunjukkan bahwa sifat alir granul pada tiap formula adalah $\mathrm{K}(+) 8$ detik, $\mathrm{K}(-) 6$ detik, FI 7 detik, F2 8 detik, F3 6 detik, F4 8 detik, dan F5 7 detik. Terjadinya variasi waktu sifat alir yang didapatkan dari tiap formula, namun masih tetap berada dalam batas persyaratan yaitu 100g/detik (Sapri, dkk. 20I2).

d. Uji sudut diam

Berdasarkan tabel 3. uji sudut diam yang diperoleh menunjukkan hasil sudut diam $\mathrm{K}(+)$ $31^{\circ}, \mathrm{K}(-) 28^{\circ}, \mathrm{FI} 30^{\circ}, \mathrm{F} 231^{\circ}, \mathrm{F} 328^{\circ}, \mathrm{F} 431^{\circ}$ dan F5 $31^{\circ}$. Persyaratan sudut diam granul memenuhi syarat apabila $25^{\circ}>\alpha<40^{\circ}$. Sudut diam $25-30^{\circ}$ masuk dalam kategori sifat aliran yang baik, sedangkan untuk sudut diam $<25^{\circ}$ masuk dalam kategori sifat alir sangat baik (Voight, 1994).

e. Uji pengetapan

Hasil yang diperoleh pada tabel 3. tiap formulasi yaitu $\mathrm{K}(+)$ sebesar 14.5\%, $\mathrm{K}(-)$ sebesar $13.9 \%$, FI sebesar 14.2\%, F2 sebesar 13.4\%, F3 sebesar 12.35\%, F4 sebesar 14.2\% dan F5 sebesar 13.18\%. Berdasarkan hasil tersebut dapat

disimpulkan bahwa kompresibilitas granul tiap formula sudah memenuhi persyaratan dan pada kriteria kompresibilitas menurut Chandira et al, (20I2) tiap formula memiliki nilai kompresibilitas yang baik.

Tabel 3. Hasil Evaluasi Granul

\begin{tabular}{ccccc}
\hline Formula & $\begin{array}{c}\text { Kadar } \\
\text { Air (\%) }\end{array}$ & $\begin{array}{c}\text { Sifat } \\
\text { Air } \\
(\text { detik) }\end{array}$ & $\begin{array}{c}\text { Pengetapan } \\
(\%)\end{array}$ & $\begin{array}{c}\text { Sudut } \\
\text { Diam } \\
\left({ }^{\circ}\right)\end{array}$ \\
\hline K (+) & 3,37 & 8 & 14,5 & 31 \\
K (-) & 3,35 & 6 & 13,9 & 28 \\
FI & 3,78 & 7 & 14,2 & 30 \\
F2 & 2,3 & 8 & 13,4 & 31 \\
F3 & 2,68 & 6 & 12,35 & 28 \\
F4 & 3,10 & 8 & 14,2 & 31 \\
F5 & & 7 & 13,18 & 31 \\
& 3,08 & & & \\
\hline
\end{tabular}

\section{Evaluasi Tablet}

a. Pemerksaan organoleptic tablet

Berdasarkan tablet yang didapat pada setiap formula berwarna putih. Tablet yang dihasilkan berbentuk bulat yang disebabkan oleh alat pencetak tablet yang berbentuk bulat. Tablet tidak berbau karena zat aktif dan bahan tambahan yang digunakan tidak memiliki bau yang khas.

Tabel 4. Hasil uji pemeriksaan organoleptis tablet

\begin{tabular}{llll}
\hline \multirow{2}{*}{ Formulasi } & \multicolumn{3}{l}{ Pemeriksaan Organoleptik } \\
\cline { 2 - 4 } & Bentuk & Warna & Bau \\
\hline K (+) & Bulat & Putih & Tidak berbau \\
\hline K (-) & Bulat & Putih & \\
\hline FI & & & Tidak berbau \\
\hline & & & Tidak berbau \\
\hline
\end{tabular}


Tidak berbau

F2 Bulat Putih

Tidak berbau

F3 Bulat Putih

Tidak berbau

F4 Bulat Putih

Tidak berbau

F5 Bulat Putih

b. Keseragaman bobot

Hasil yang didapatkan pada tiap formula memiliki bobot rata-rata sebesar 600 gram, bobot tersebut masuk dalam kategori bobot $>300$ yaitu tidak boleh lebih dari 2 tablet yang masing-masing bobotnya menyimpang dari bobot rata-ratanya lebih besar dari $5 \%$ dan tidak boleh satu tablet pun yang bobotnya menyimpang dari bobot rataratanya lebih dari $10 \%$ menurut Farmakope Indonesia Edisi Ketiga.

Berdasarkan hasil uji keseragaman bobot formula $\mathrm{K}(+)$, FI, F3 dan F5 sudah memenuhi persyaratan keseragaman bobot yang telah ditetapkan. Pada Formula $\mathrm{K}(-)$, F2 dan F4 tidak memenuhi persyaratan keseragaman bobot, hal ini dapat disebabkan karena ketidakseragaman pengisian tempat dikempanya granul menjadi tablet, yang berkaitan erat dengan sifat alir granul (Siti Khalidah, dkk. 2014).

Data hasil uji keseragaman bobot yang diperoleh dilakukan uji normalitas data dengan uji Kolmogorov-Smirnov. Hasil uji yang diperoleh memperlihatkan bahwa data tidak terdistribusi normal dengan nilai sebesar $0.002(0.002<0.05)$. Uji yang dilakukan untuk mengetahui perbedaan yang bermakna antar formula adalah Kruskal-Wallis $H$. Hasil uji menunjukkan nilai signifikan 0.000 sehingga dapat disimpulkan bahwa keseragaman bobot tiap formula terdapat perbedaan yang bermakna.

c. Kekerasan tablet

Kekerasan dinyatakan dalam satuan $(\mathrm{kg})$ dari tenaga yang dibutuhkan untuk memecah tablet. Persyaratan kekerasan tablet secara umum yaitu 48 kg (Winda, dkk. 2016). Berdasarkan hasil pada uji kekerasan tablet formula $\mathrm{K}(+), \mathrm{K}(-), \mathrm{FI}$ dan F2 memiliki kekerasan tablet yang sudah memenuhi persyaratan. Formula F3, F4 dan F5 tidak memenuhi persyaratan. $\mathrm{Hal}$ ini dapat terjadi karena dipengaruhi oleh tekanan pencetakan, lubrikan, bentuk dan ukuran diameter punch (Effionora Anwar, dkk. 2004).

Data hasil uji kekerasan tablet yang diperoleh dilakukan uji normalitas data dengan uji Shapiro Wilk. Hasil uji yang diperoleh memperlihatkan data tidak terdistribusi normal dengan nilai signifikan $0.002(0.002<0.05)$. Uji yang dilakukan untuk mengetahui perbedaan yang bermakna antar formula adalah Kruskal-Wallis $H$. Hasil uji menunjukkan nilai signifikan 0.005 bahwa kekerasan tablet tiap formula terdapat perbedaan yang bermakna.

d. Kerapuhan tablet

Pesyaratan untuk kerapuhan tablet yaitu kehilangan berat lebih kecil dari $0.5 \%$ sampai $1 \%$ masih dapat dibenarkan (Gloria dan yetri, 2018). Berdasarkan tabel 4 hasil uji kerapuhan tablet menunjukkan bahwa formula $\mathrm{K}(+)$, FI dan F5 sudah memenuhi persyaratan, sedangkan formula K(-), F2, F3 dan F4 tidak memenuhi persyaratan. Hal ini dapat disebabkan karena tablet yang tidak terkempa dengan baik (Dewo Elfira, dkk. 2017). Selain itu kerapuhan juga dipengaruhi oleh proses pengempaan yang semakin tinggi tekanan diberikan pada saat pengempaan maka tablet yang dihasilkan akan semakin kompak sehingga kerapuhannya kecil dan sebaliknya jika tekanan yang diberikan kecil 
maka tablet yang dihasilkan memiliki kerapuhan yang tinggi (Devi, dkk. 2018).

Data hasil uji dianalisis dengan uji One-way ANOVA dan diperoleh hasil yang signifikan dengan nilai signifikan 0.000 bahwa kerapuhan tablet tiap formula memang berbeda bermakna. Data selanjutnya dilakukan uji LSD, hasil uji LSD adanya perbedaan antar formula.

e. Waktu hancur tablet

Berdasarkan hasil pada yang didapatkan pada tiap formula adalah $\mathrm{K}(-), \mathrm{K}(+), \mathrm{FI}$ dan F5 sudah memenuhi persyaratan waktu hancur tablet tidak bersalut, sedangkan formula F2, F3 dan F4 tidak memenuhi persyaratan yang telah ditetapkan untuk tablet tidak bersalut. Persyaratan untuk waktu hancur tablet tidak bersalut menurut Farmakope Indonesia Edisi Ketiga adalah semua tablet harus tidak lebih dari 15 menit. Ketidaksesuaian hasil pada formula F2, F3 dan F4 dapat disebabkan oleh kekerasan tablet karena semakin keras tablet maka semakin lama waktu yang dibutuhkan suatu tablet untuk hancur, hal ini sesuai dengan hasil kekerasan tablet pada formula tersebut yang lebih besar daripada formula lainnya (Sugiyono, dkk. 2016). Selain itu, konsentrasi pati juga mempengaruhi lama waktu hancur tablet karena penggunaan pati dapat mempercepat penyerapan air sehingga memungkinkan untuk dapat menarik air melalui kerja kapiler (Bayu Heris, dkk. 2017).

Data hasil uji dianalisis dengan uji One-way ANOVA dan diperoleh hasil yang signifikan dengan nilai signifikan 0.000 bahwa kerapuhan tablet tiap formula memang berbeda bermakna. Data selanjutnya dilakukan uji LSD, hasil uji LSD adanya perbedaan antar formula.

Tabel 5.hasil evaluasi sifat fisik tablet

\begin{tabular}{ccccc}
\hline Form & Keseragama & Kekera & Kerapu & Wakt \\
ula & n bobot & san & han & $u$ \\
\hline
\end{tabular}

\begin{tabular}{|c|c|c|c|c|c|}
\hline & $\begin{array}{l}\text { Kolo } \\
\text { m A } \\
(5 \%)\end{array}$ & $\begin{array}{c}\text { Kolo } \\
\text { m B } \\
(10 \% \\
)\end{array}$ & $\begin{array}{c}\text { tablet } \\
(\mathrm{kg})\end{array}$ & $\begin{array}{c}\text { tablet } \\
(\%)\end{array}$ & $\begin{array}{c}\text { hanc } \\
\text { ur } \\
\text { (men } \\
\text { it) }\end{array}$ \\
\hline $\mathrm{K}(+)$ & I & 0 & 5,6 & 0,9 & 14 \\
\hline K (-) & 7 & 0 & 4,4 & 2 & 12 \\
\hline $\mathrm{FI}$ & 0 & 0 & 5,2 & 0,7 & 14 \\
\hline $\mathrm{F} 2$ & 6 & 0 & 7,8 & 1,2 & 17 \\
\hline F3 & 0 & 0 & 8,9 & 1,6 & 16 \\
\hline $\mathrm{F} 4$ & 4 & 0 & 8,5 & 2 & 17 \\
\hline F5 & 0 & 0 & 8,7 & I & 15 \\
\hline
\end{tabular}

\section{KESIMPULAN}

Kesimpulan yang dapat diambil berdasarkan hasil penelitian tentang Evaluasi "Pengaruh Variasi Konsentrasi Pati Biji Cempedak (Arthocarpus Champeden) Sebagai Bahan Pengisi Pada Formulasi Tablet Paracetamol" yaitu Pati biji cempedak (Arthocarpus champeden) dapat digunakan sebagai bahan pengisi pada pemuatan tablet Paracetamol.

\section{UCAPAN TERIMA KASIH}

Terimaksih banyak kepada keuda orang tua saya serta kepada segenap keluarga yang selalu memberikan dukungan hingga akhirnya bias sampai menyelesaikan penelitian ini. Terimakasih banyak juga kepada sahabatsahabat yang selalu memberikan semangat, bantuan serta motivasi tanpa henti kepada penulis dalam menyelesaikan penelitian in

\section{REFERENSI}

I. Nor Laili, A. M. 2017. Optimasi Konsentras Amylum Sagu (Metroxylon Rumphii) Sebagai CoProcessed Pada Pembuatan Tablet Teofilin. Pharmacon: Jurnal Farmasi Indonesia. Vol 14 No.2 ISSN / 4 I I-4283.

2. Hortikultura, D. J. 2015. Statistik Produksi Hortikultura Tahun 20/4. Direktorat Jenderal Hortikultura. 
3. Noval, N., Yuwindry, I., \& Syahrina, D. (2019). Phytochemical Screening and Antimicrobial Activity of Bundung Plants Extract by Dilution Method. Jurnal Surya Medika. https://doi.org//0.33084/jsm.v5il.954

4. Noval, Noval, Melviani Melviani, Novia Novia, and Dahlia Syahrina. 2020. "Formulasi Dan Evaluasi Sediaan Obat Kumur (Mouthwash) Dari Ekstrak Etanol Tanaman Bundung (Actinoscirpus Grossus) Sebagai Antiseptik Mulut”. Jurnal Surya Medika (JSM) $6 \quad$ (I), I $2-20$. https://doi.org// 0.33084/jsm.v6il.1626..

5. Samar A. Afifi, D. 2013. Comperative Evalution Of The Pharmaceutical And Chemical Equivalence Of Some Cemmercial Brands Of Acetaminophen Tablets. Life Science Journal; 10(3).

6. Sugiono, S. K. 2016. Formulasi Tablet Paracetamol Menggunakan Tepung Bonggol Pisang Kepok (Musa Paradisiaca Cv, Kepok) Sebagai Bahan Pengikat.

7. Kurniawati, Darini, Noval Noval, and Kunti Nastiti. 2020. "POTENSI ANTISEPTIK POLIHERBAL DAUN SIRIH (Piper Betle), KULIT JERUK NIPIS (Citrus Aurantifolia) DAN TANAMAN BUNDUNG (Actinuscirpus Grossus) PADA TINDAKAN KEPERAWATAN DAN KEBIDANAN." Dinamika Kesehatan: Jurnal Kebidanan Dan Keperawatan I I(I): 420-3I.

8. Nailul Maghfiroh, D. E. 2018. Optimasi Kombinasi Pati Umbi Gembili (Dioscorea Esculenta (Lour.) Burk) Dan Umbi Ganyong (Canna Edulis Ker,) Sebagai Bahan Pengisi Tablet Ibuprofen Dengan Metode Simplex Lattice Design. J Pharm Sci Clin Res :02.

9. Sapri, D. S. 2012. Pengaruh Penggunaan Pati Biji Cempedak (Arthocarpus Champeden Lour) Sebagai Bahan Pengikat Terhadap Sifat Fisik Tablet Paracetamol Secara Granulasi Basah. J. Trop. Pharm. Chem. Vol 2 No I.

10. Noval, N., Nastiti, K., Nugraha, D., Rahmadani, R., \& Alawiyah, T. (2020). PRODUK INOVASI HAND SANITIZER DARI AKAR BAIAKAH SEBAGAI UPAYA PENCEGAHAN DI MASA PANDEMI COVID-19. LOGISTA - lurnal Ilmiah Pengabdian Kepada Masyarakat, 4(2), 305-3I2. doi: | 0.25077/logista.4.2.305-3 | 2.2020

II. Depkes, R. 1979. Farmakope Indonesia Edisi lii. Jakarta: Departemen Kesehatan Republik Indonesia.
12. Depkes, R. 1995. Farmakope Indonesia Edisi lii. Jakarta: Departemen Kesehatan Republik Indonesia.

I3. Noorjannah, \& Noval. (2020). Uji Disolusi Terbanding Antara Sediaan Tablet Ramipril Generik dan Bermerek. Journal of Pharmaceutical Care and Science, I(I), 45-54.

14. Chandira, et. al. 2012. Formulation and Evaluation the Oral Tablets Ibuprofen. TPI JOURNAL, Vol. I No.9.

15. Siti, dkk. 20 I4. Formulasi Tablet Effervescnt Jahe ( $Z$ Officinale Roscoe) dengan Variasi Konsentrasi Sumber Asam dan Basa. Online Jurnal of Natural Science, Vol. 3(3).

16. Efffionora, dkk. 2004. Pemanfaatan Maltodekstrin Pati Terigu sebagai Eksipien dalam Formula Sediaan Tablet dan Nisosom. Majalah Ilmu Kefarmasian, Vol. I No.l.

17. Anwar, K. 2010. Formulasi Sediaan Tablet Effervescent dari Ekstrak Kunyit (Curcuma domestica Val.) dengan Variasi Jumlah Asam SitratAsam Tartrat sebagai Sumber Asam. Sains dan Terapan Kimia, Vol.4 No.2.

18. Dewi Rashati, A. F. 2017. Pengaruh Variasi Konsentrasi Amilum Zea Mays (L) Sebagai Bahan Penghancur Secara Granulasi Basah Terhadap Sifat Fisik Tablet Paracetamol.

19. Devi, dkk. 2018. Optimasi Konsentrasi Polivinil (PVP) sebagai Bahan Pengikat terhadap Sifat Fisik Tablet Ekstrak Etanol Rimbang Bangle (Zingiber cassumunar Roxb). Jurnal Farmasi Udayana, Vol. 7 No. 2.

20. Bayu, dkk. 2017. Evaluasi Pati Umbi Talas (Colocasia esculenta Schott) sebagai Bahan Pengisi pada Sediaan Tablet Paracetamol. Proceeding of the 5th Mulawarman Pharmaceuticals Conferences. 